\title{
AMINO ACID SEQUENCE OF CARBOXYPEPTIDASE Y. II. PEPTIDES FROM ENZYMATIC CLEAVAGES
}

\author{
by \\ IB SVENDSEN, BRIAN M. MARTIN"), THAMMAIAH VISWANATHA ${ }^{2)}$, \\ and JACK T. JOHANSEN ${ }^{3)}$ \\ Carlsberg Laboratory, Department of Chemistry, \\ Gamle Carlsberg Vej 10, DK-2500 Copenhagen Valby \\ 1) Present address: Max-Planck Institute für Ernährungsphysiologie, \\ Rheinlanddamm 201, D-4600 Dortmund 1. W. Germany \\ 2) Present address: Department of Chemistry, University of Waterloo, \\ Waterloo, Ontario, Canada N2L 3G1 \\ 3) Carlsberg Biotechnology Ltd. A/S \\ Tagensvej 16, DK-2200 Copenhagen N
}

Keywords: Carboxypeptidase Y, amino acid sequence, yeast

Carboxypeptidase $Y$ (E.C.3.4.12.1) with the lysine side-chains blocked by citraconylation has been digested with trypsin and the resulting peptides purified by gel filtration followed by ion-exchange chromatography on DE 52 cellulose. Eight of the expected ten peptides have been completely or partially sequenced in a liquid phase automatic sequencer. The remaining two peptides were sequenced as part of a $\mathrm{CNBr}$ peptide (see preceeding paper). Selected peptides obtained from enzymatic cleavages with A. mellea protease, chymotrypsin, post-proline cleaving enzyme, S. aureus V8 protease, and subtilisin have upon sequencing provided overlaps which have made the reconstruction of $96 \%$ of the complete sequence possible together with a tentative assignment of the carbohydrate attachment sites. No homology with sequences of known proteases has been observed.

\footnotetext{
Abbreviations: ConA $=$ Concanavalin A; CPD-Y $=$ carboxypeptidase $\mathrm{Y} ;$ DPCC $=$ diphenyl carbamylchloride; EDTA $=$ ethylenediamine tetraacetate; HEPES $=\mathrm{N}$-2-hydroxyethylpiperazine- $\mathrm{N}-2$ ethanesulfonic acid; HPLC $=$ high pressure liquid chromatography: THEED $=\mathbf{N}, \mathbf{N}, \mathrm{N}^{\prime}, \mathrm{N}^{\prime}$-tetrakis (2hydroxyethyl)ethylene diamine; TLCK = tosyllysyl chloromethylketone.
} 


\section{INTRODUCTION}

The N-terminal and C-terminal amino acid sequences of carboxypeptidase Y (CPD-Y) have already been published together with a short sequence which includes the active site serine residue $(8,13)$. The preceeding paper describes the amino acid sequences obtained from cleavage with cyanogen bromide (17). This paper presents the results from sequence studies of peptides obtained by tryptic cleavage and selected peptides obtained from hydrolysis with A.mellea protease, chymotrypsin, post-proline cleaving enzyme, S.aureus V8 protease, and subtilisin Carlsberg. The amino acid sequences described in this and the preceeding paper permit the reconstruction of about $96 \%$ of the complete sequence of CPD-Y which consists of approximately $\mathbf{4 3 0}$ residues. The tentative assignment of the four points of attachment of the carbohydrate moieties is given.

\section{MATERIALS AND METHODS}

\subsection{Materials}

Carboxypeptidase $\mathrm{Y}$ was prepared as described by JoHANSEN et al. (10) from baker's yeast obtained from De Danske Spritfabrikker. Trypsin treated with diphenylcarbamylchloride was a product of Sigma, Ill., USA, as was tosyllysylchloromethylketone. Chymotrypsin and subtilisin Carlsberg were gifts from Novo Industries, Copenhagen, Denmark, post-proline cleaving enzyme was obtained from Miles, Slough, U.K., and A.mellea protease was a gift from VIBEKE Barkholt Pedersen, Institute of Molecular Genetics, University of Copenhagen, Denmark. Reagents used with the sequencer were from Pierce, Rotterdam, Holland, except THEED which was obtained from CN-K \& $\mathrm{K}$ Laboratories, New York, USA, heptane which was from Fluka, Switzerland, and ethylacetate which was from Merck, Darmstadt, W. Germany. DE 52 cellulose was a product of Whatman, Maidstone, U.K., and Biogels P60, P10, and P6 were bought from Biorad, Cal., USA. Sephadex G50, G25, Sepharose $4 B$, and ConA-Sepharose came from Pharmacia, Uppsala, Sweden. All other reagents were analytical grade products.

\subsection{Methods}

\subsubsection{Reduction and alkylation}

$500 \mathrm{mg}$ of enzyme was reduced with dithiothreitol $(50 \mathrm{mg}$ ) under nitrogen for 4 hours at $\mathrm{pH}$ 8.6 and $35^{\circ} \mathrm{C}$. Then, $\mathrm{pH}$ was adjusted to 7.3 and the enzyme treated with 4-vinylpyridine for 90 min. (5). The reaction was terminated by adjusting the $\mathrm{pH}$ to 3.0 with glacial acetic acid. The sample was finally dialyzed against $10 \mathrm{~mm}$ acetic acid and lyophilized.

\subsubsection{Digestion with trypsin}

Before digestion with trypsin the $\varepsilon-\mathrm{NH}_{2}$ groups of the lysines were blocked by citraconylation according to Dixon (2) and the product dialyzed against water adjusted to $\mathrm{pH} 8.5-8.8$ with ammonia. Complete reaction with the lysine side-chains was ascertained by dansylation of an aliquot; no dansylated lysine was present after acid hydrolysis.

Digestion with DPCC-treated trypsin was conducted in the $\mathrm{pH}$-stat at $\mathrm{pH}$ 8.0. The enzyme to substrate ratio was $1: 100(\mathrm{w} / \mathrm{w})$. When the base-consumption ceased a new addition of trypsin was made and the reaction mixture was left for an additional $60 \mathrm{~min}$. Addition of TLCK (25:1 $\mathrm{mol} / \mathrm{mol}$ ) ensured complete inhibition of the trypsin. The digest was finally lyophilized.

\subsubsection{Gelfiltration of tryptic digest}

The digest was only partly soluble in $30 \%$ acetic acid. Therefore, the suspension was centrifuged and the precipitate and supernatant treated individually. The supernatant was applied to a Biogel P60 column $(2.6 \times 100 \mathrm{~cm})$ equilibrated with $30 \%$ acetic acid. $5 \mathrm{ml}$ fractions were collected with a flow-rate of approximately $5 \mathrm{ml} \cdot \mathrm{hr}^{-1}$. The optical density at $280 \mathrm{~nm}$ was measured and the relevant peaks pooled and lyophilized. The precipitate from the digest was soluble in $10 \%$ acetic acid containing 6 m-urea and was fractionated as above except that $6 \mathrm{M}$ urea was present in the elution medium. The individual peaks were then desalted on a Biogel P6 column $(1.5 \times 28 \mathrm{~cm})$ equilibrated with $30 \%$ acetic acid and lyophilized.

\subsubsection{Ion-exchange chromatography of tryptic peptides}

Each of the peaks resulting from the gel filtration were subjected to further purification 
by ion-exchange chromatography on DE 52 cellulose columns $(0.9 \times 26 \mathrm{~cm})$. The column was first eluted with $40 \mathrm{ml}$ of a $0.03 \mathrm{M}$ ammonium acetate buffer, $\mathrm{pH} 6.5,6 \mathrm{~m}$ in urea, followed by a linear gradient consisting of $50 \mathrm{ml}$ of this buffer and $50 \mathrm{ml}$ of a $0.5 \mathrm{M}$-ammonium acetate buffer, $\mathrm{pH} 6.5,6 \mathrm{~m}$ in urea. The optical density at $280 \mathrm{~nm}$ was measured and the located peaks pooled, desalted on a Biogel P6 column $(1.5 \times 28 \mathrm{~cm})$ equilibrated with $30 \%$ acetic acid and lyophilized.

\subsubsection{Digestion with A.mellea protease (15)}

Reduced, pyridylethylated CPD-Y (15 mg) was dissolved in $3.5 \mathrm{ml} 0.2 \mathrm{M}$-ammonium bicarbonate buffer, $\mathrm{pH} 8.0$, and treated with $\mathrm{A}$. mellea protease $(0.2 \mathrm{mg})$ for 16 hours at $37^{\circ} \mathrm{C}$. The reaction was stopped by adding $0.5 \mathrm{ml} 2 \mathrm{M}$ EDTA. The digest was chromatographed on a Sephadex G50 (fine) column $(2 \times 100 \mathrm{~cm})$ equilibrated and eluted with $10 \mathrm{~mm}$-ammonium bicarbonate at a flow-rate of $20 \mathrm{ml} \cdot \mathrm{hr}^{-1}$. The resulting peaks were pooled separately and lyophilized.

In a separate experiment the digest was passed over a column of ConA-Sepharose $(1 \times 4 \mathrm{~cm})$ equilibrated and eluted with a 0.1 M-HEPES buffer containing $1 \mathrm{~mm}$ of $\mathrm{Mn}^{++}, \mathrm{Ca}^{++}$, and $\mathrm{Mg}^{++}$. Fractions containing unretarded peptides were pooled and lyophilized. Retained peptides were eluted with the same buffer containing 0.1 $M-\alpha$-methylmannoside, relevant fractions pooled and lyophilized. Both groups of peptides were subjected to gel filtration as described above and the resulting peaks pooled and lyophilized.

Additional purification of selected peptides was achieved by ion-exchange chromatography on a Whatman DE52 cellulose column $(1 \times 60$ $\mathrm{cm}$ ) developed with a potassium phosphate buffer, $\mathrm{pH} 7.5$, and a linear gradient of $\mathrm{NaCl}$ from 0 to $0.8 \mathrm{M}$. The resulting peaks were pooled, desalted on a Sephadex G25 column equilibrated with $30 \%$ acetic acid and lyophilized.

\subsubsection{Digestion with chymotrypsin}

Cleavage with this enzyme was performed as described above except that chymotrypsin was used. The resulting mixture of peptides were separated on a Sephadex G50 (superfine) column $(2 \times 80 \mathrm{~cm})$ in $30 \%$ acetic acid followed by
Sepharose 4B $(2 \times 90 \mathrm{~cm})$ in $0.01 \mathrm{M}-$ ammonium bicarbonate.

\subsubsection{Digestion with post-proline cleaving enzyme}

Cyanogen bromide peptide $\mathrm{CNBr}-\mathrm{II}$ (17), 500 nmoles, was dissolved in $1 \mathrm{ml} 0.1 \mathrm{M}$-ammonium bicarbonate, $\mathrm{pH} 7.0$ containing $1 \mathrm{~mm}$-dithiothreitol and $1 \mathrm{~mm}$-EDTA. The enzyme $(25 \mu \mathrm{l}, 2.5$ units) was added and the reaction mixture left overnight at $39^{\circ} \mathrm{C}$ after which it was applied to a Biogel P10 column $(0.9 \times 95 \mathrm{~cm})$ equilibrated and eluted with $0.1 \mathrm{M}$-ammonium bicarbonate buffer. The resulting peaks were pooled and lyophilized.

\subsubsection{Digestion with subtilisin}

CPD-Y (25 mg) was dissolved in $3 \mathrm{ml} 0.1 \mathrm{M}-$ phosphate buffer, pH 6.7, and $60 \mu$ l subtilisin Carlsberg (stock solution $1 \mathrm{mg} \cdot \mathrm{ml}^{-1}$ ) was added. The reaction mixture was left for two hours and then lyophilized. The lyophilized material was treated with $1.4 \mathrm{ml}$ of performic acid for two hours, diluted with $30 \mathrm{ml}$ of $\mathrm{H}_{2} \mathrm{O}$ and lyophilized, redissolved in $30 \%$ acetic acid and centrifuged in order to remove insoluble material (gelatinous precipitate). The supernatant was then applied to a column of Biogel P30 $(2 \times 85 \mathrm{~cm})$ equilibrated with $30 \%$ acetic acid.

\subsubsection{Digestion with $S$. aureus $V 8$ protease (3)}

$0.5 \mathrm{mg}$ of peptide to be digested was dissolved in $1 \mathrm{ml} 0.1 \mathrm{M}$-ammonium bicarbonate, $\mathrm{pH} 7.8$. Enzyme was added $(50 \mu \mathrm{g})$ and the reaction mixture left for five hours at $40^{\circ} \mathrm{C}$. The volume was reduced to $200 \mu \mathrm{l}$ and applied to a reverse phase column (Water's $\mu$ Bondapak $\mathrm{C}_{18}$ ). The HPLC separation system was developed with an acetonitrile gradient from 0 to $80 \%$ (both solvents being $0.1 \%$ in trifluoroacetic acid). Flow-rate was $1 \mathrm{ml} \cdot \mathrm{min}^{-1}$ and absorbance was measured at $220 \mathrm{~nm}$. The relevant fractions were pooled and rechromatographed in the same system.

\subsubsection{Digestion with carboxypeptidase $Y$}

C-terminal amino acid sequence determination was made with carboxypeptidase $\mathrm{Y}$ as described by MARTIN et al. (16). 


\subsubsection{Amino acid analyses}

Acid hydrolysis was performed with $5.7 \mathrm{M}$ $\mathrm{HCl}$ in evacuated and sealed tubes for 24 hours. Amino acid analysis were made on a Durrum, model 500, amino acid analyzer. No corrections were made for losses in yields of Ser and Thr. Trp was not determined. In the chromatographic system used, pyridylethylcysteine eluted as a shoulder on the descending limb of lysine and thereby made an accurate determination of these amino acids difficult.

\subsubsection{Amino acid sequencing}

A Beckman, model $890 \mathrm{C}$, liquid phase sequencer was used for amino acid sequence determinations as described by JoHANSEN et al. (11). Identification of the PTH-amino acids was made by HPLC as described by SVENDSEN et al. (20). Additional information was obtained by thin layer chromatography on polyamide sheets according to KULBE (14) or by back hydrolyses to the free amino acids as described by MENDEZ and LAI (18). For peptides shorter than 50 residues Polybrene was added in order to minimize extractive losses of peptide material (12).

\subsubsection{Carbohydrate analysis}

Carbohydrates were detected by the phenolsulphuric acid method of DuBors (4) or by the appearance of glucosamine in the amino acid hydrolysates.

\section{RESULTS}

\subsection{Gel filtration of tryptic peptides}

An attempt to dissolve the lyophilized mixture of tryptic peptides completely in $30 \%$ acetic acid was unsuccessful. The disperse solution was consequently centrifuged and the clear supernatant applied to a Biogel P30 column. The elution pattern is seen in Figure 1. The precipitate dissolved readily in $30 \%$ acetic acid which contained $6 \mathrm{M}$-urea. Gel filtration in this solvent gave rise to the same peaks as shown in Figure 1, but the proportions of the various peptides differed in such a way that the large peptides were found primarily in the precipitate while the small peptides were more soluble in the urea free medium.

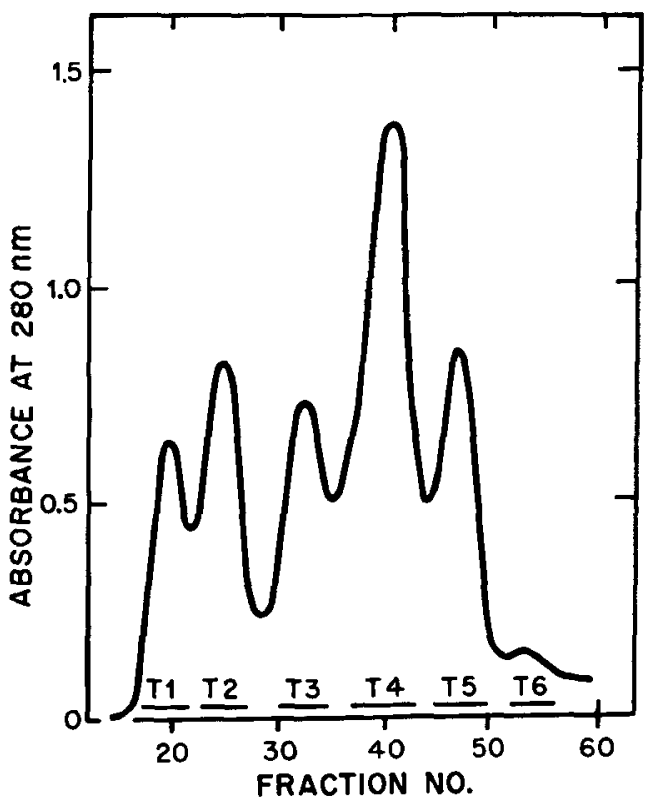

Figure 1. Gel filtration of tryptic peptides of carboxypeptidase $\mathrm{Y}$ on Biogel P60 in $30 \%$ acetic acid.

Column dimension $2.6 \times 100 \mathrm{~cm}$. Five $\mathrm{ml}$ fractions were collected with a flow-rate of $5 \mathrm{ml} \cdot \mathrm{hr}^{-1}$. Fractions pooled as indicated by bars and numbered $\mathrm{T} 1$ to $\mathrm{T} 6$ in the order of elution.

\subsection{Chromatography on DE 52 cellulose}

Following desalting, when necessary, each of the six peaks $\left(T_{1}-T_{6}\right)$ from gel filtration was subjected to ion-exchange chromatography on DE 52 cellulose as described below.

Pool T1. The pool containing the largest of the tryptic peptides consisted of two peptides and sequence analysis showed them to be the $\mathrm{N}$ terminal peptide Lys-Ile-Lys--- and a peptide beginning with Asn-Asp-Pro-... It was not possible to separate the two peptides by chromatography on DE cellulose or by isoelectric focusing. Cleavage of the peptide mixture with $\mathrm{CNBr}$ revealed two additional peptides starting with Ala-Cys-Gly--- and Glu-Asp-Ser-... These two short $\mathrm{CNBr}$-peptides (see below) are contained in another tryptic peptide starting AsnPhe- ? -Leu--- (see Table I, T3-6). Thus, it appears that $T 1$ is an aggregate of peptides partially cleaved at the arginine residues.

Since the sequence of the N-terminal tryptic 
Table I

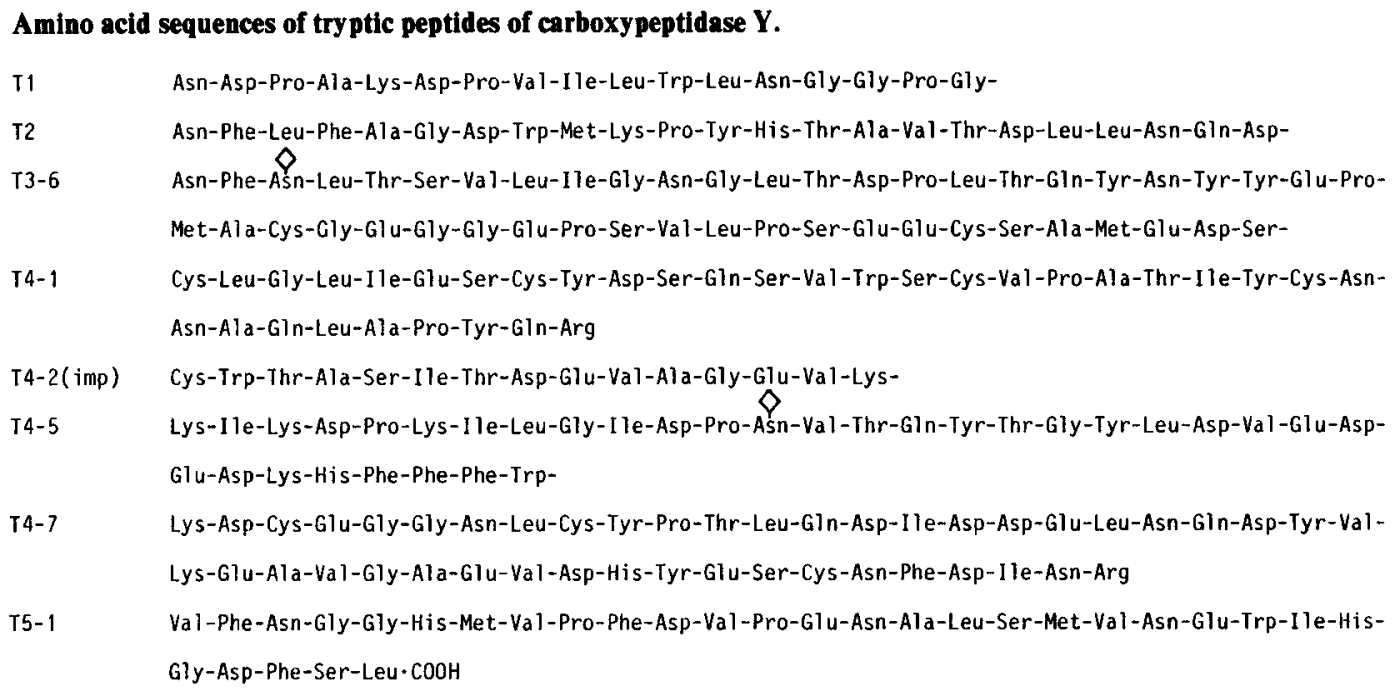

peptide of 38 residues of CPD-Y was already known (17) it was possible to obtain part of the other sequence in $\mathrm{T} 1$ which could be followed 29 steps (see Table I, T1).

Pool T2. Ion-exchange chromatography of T2 gave rise to four components which were pooled as shown in Figure 2. Sequence determination showed that all four peaks had the same $\mathrm{N}$ terminal sequence and $\mathrm{C}$-terminal sequence. The amino acid compositions were also identical. Carbohydrate was present in all four peptides and may, together with charge differences, be the cause of the same peptide appearing in four positions. The peptide was sequenced 23 steps. As seen in Table I, T2 an overlap to an already sequenced $\mathrm{CNBr}$-peptide (17) was found from the ninth cycle. The peptide is approximately 110 residues long and contains two arginine residues and thus represents an incomplete cleavage product.

Pool T3. Ion-exchange chromatography of T3 revealed six peptides. Four of these contained the sequence found in T2, but contaminated with the $\mathrm{N}$-terminal tryptic peptide and in small quanti- ties. One peptide, T3-6 was clean and represented a new sequence which was determined for 48 residues. Then an overlap with $\mathrm{CNBr}$-peptide

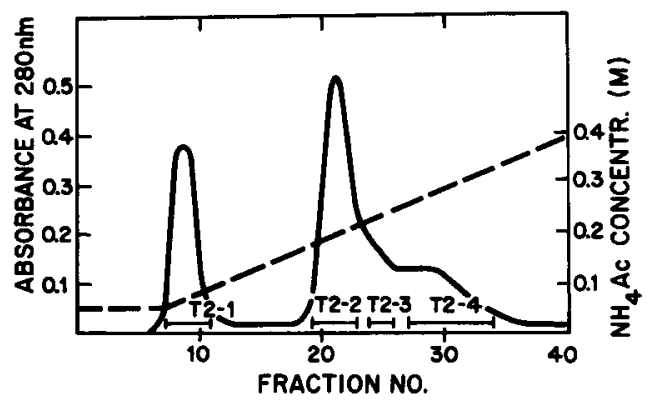

Figure 2. Ion-exchange chromatography of tryptic peptides pool T2, from the gel filtration, on DE 52 cellulose $(0.9 \times 26 \mathrm{~cm})$ equilibrated with $0.03 \mathrm{M}$ ammonium acetate, $\mathrm{pH} 6.5,6 \mathrm{~m}$ in urea.

First, $40 \mathrm{ml}$ of this buffer was passed through the column followed by a linear gradient consisting of 50 $\mathrm{ml}$ starting buffer and $50 \mathrm{ml} 0.5 \mathrm{M}$-ammonium acetate buffer, $\mathrm{pH} 6.5,6 \mathrm{~m}$ in urea. Fractions of 2.5 $\mathrm{ml}$ were collected with a flow-rate of $12 \mathrm{ml} \cdot \mathrm{hr}^{-1}$. Fractions pooled as shown by bars. 
Table II

Amino acid composition of tryptic peptides from CPD-Y.

\begin{tabular}{|c|c|c|c|c|c|c|}
\hline $\begin{array}{l}\text { Amino } \\
\text { acid }\end{array}$ & $\mathrm{T}-2$ & T3-6 & T4-1 & T4-5 & T4.7 & T5-1 \\
\hline Asp & $13(13)$ & $6(5)$ & $3(3)$ & $6(6)$ & $10(10)$ & $4(5)$ \\
\hline Thr & $5(5)$ & $3(3)$ & $1(1)$ & $3(3)$ & $1(1)$ & $0(0)$ \\
\hline Ser & $4(3)$ & $5(5)$ & $4(4)$ & $1(1)$ & $1(1)$ & $2(2)$ \\
\hline Glu & $6(6)$ & $8(8)$ & $4(4)$ & $4(4)$ & $6(7)$ & $2(2)$ \\
\hline Pro & $4(3)$ & $4(4)$ & $2(2)$ & $2(2)$ & $1(1)$ & $2(2)$ \\
\hline Gly & $5(4)$ & $5(5)$ & $1(1)$ & $2(2)$ & $3(3)$ & $3(3)$ \\
\hline Ala & $7(7)$ & $2(2)$ & $3(3)$ & $0(0)$ & $2(2)$ & $1(1)$ \\
\hline Val & $5(6)$ & $2(2)$ & $2(2)$ & $2(2)$ & $3(3)$ & $4(4)$ \\
\hline Met & $1(1)$ & $2(2)$ & $0(0)$ & $0(0)$ & $0(0)$ & $2(2)$ \\
\hline Ile & $4(3)$ & $1(1)$ & $2(2)$ & $3(3)$ & $2(2)$ & $1(1)$ \\
\hline Leu & $9(8)$ & $6(6)$ & $3(3)$ & $2(2)$ & $3(3)$ & $2(2)$ \\
\hline Tyr & $5(5)$ & $3(3)$ & $3(3)$ & $2(2)$ & $3(3)$ & $0(0)$ \\
\hline Phe & $5(5)$ & $1(1)$ & $0(0)$ & $4(4)$ & $1(1)$ & $3(3)$ \\
\hline $\mathrm{His}$ & $2(2)$ & $0(0)$ & $0(0)$ & $1(1)$ & $1(1)$ & $2(2)$ \\
\hline Lys") & $7(7)$ & $0(1)$ & $0(3)$ & $4(4)$ & $5(2)$ & $0(0)$ \\
\hline Arg & $2(2)$ & $1(1)$ & $1(1)$ & $1(1)$ & $1(1)$ & $0(0)$ \\
\hline Trp & n.d. ( 4) & n.d. (0) & n.d. (1) & n.d. (1) & n.d. ( 0$)$ & n.d. (1) \\
\hline Cys & (1) & (2) & (4) & (0) & ( 3 ) & (0) \\
\hline
\end{tabular}

The first figure-column denotes amino acid composition (residues per mole) determined by amino acid analysis and expressed as nearest integer while the figures in brackets denote composition obtained from sequence data. 1) Determined as the sum of Lys and 4-pyridylethylated cystein.

CNBr I-II was established (see Table I, T3-6 and (17)). In addition the sequence also contains a CNBr-peptide of 19 residues not prior sequenced. Amino acid analysis showed that the peptide contained carbohydrate. Since CNBr I-II

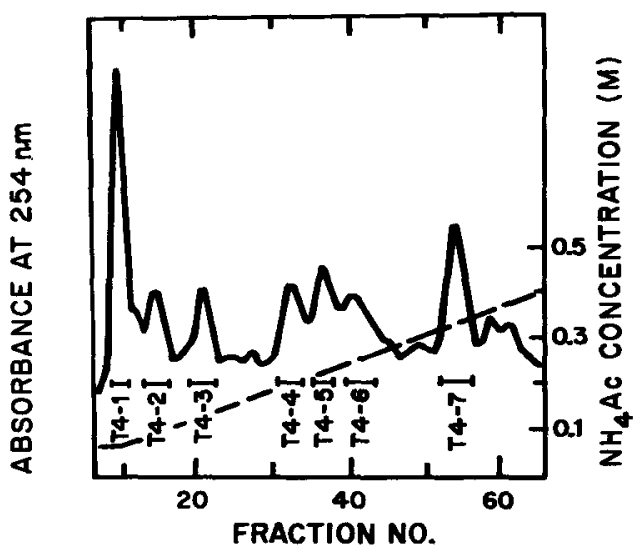

Figure 3. Ion-exchange chromatography of tryptic peptides pool $\mathrm{T} 4$ from the gel filtration, on $\mathrm{DE} 52$ cellulose. Conditions as in Figure 2. contains an Arg in position 6 it is possible to obtain the exact amino acid composition of $T 3-6$ from the sequence data. A good agreement is found between this value and the one obtained from amino acid analysis (Table II).

Pool T4. This pool of peptides separated into seven main peaks (see Figure 3). The first three peptides (T4-1, T4-2 and T4-3) all started with the same sequence: Cys-Leu-Gly which is a sequence already known as part of cyanogen peptide CNBr I-II (17). The amino acid composition of T4-1 agrees well with the known sequence (see Table II).

One of the peptides described above (T4-2) contained an impurity the sequence of which could be followed for 15 cycles (see Table I, T42 (imp)).

The peptides T4-4, T4-5 and T4-6 were identical in amino acid composition and all contained glucosamine indicating the presence of carbohydrate. Sequence determination of T4-5 showed that it was the $\mathrm{N}$-terminal peptide of CPD-Y. The sequence of 33 residues was established which confirmed the already known 
sequence (see Table I). A comparison of the amino acid composition based on acid hydrolysis and sequence studies is shown in Table II.

According to the amino acid composition peptide T4-7 consisted of approximately 45 residues and was devoid of amino sugars. It was sequenced almost to the end from its $\mathrm{N}$-terminal (see Table I, T4-7), and the sequence was completed by treatment with CPD-Y (see Table I). As seen in Table II a good correspondence between sequence and amino acid analysis exists.

Pool T5. Amino acid analysis of this peptide pool showed that Arg was absent and hence it represented the C-terminal part of CPD-Y. Ionexchange chromatography gave rise to three peaks which all had the same amino acid composition of approximately 30 residues. The peptide (T5-1) was sequenced 24 cycles revealing two methionine residues. Consequently, another sample was acetylated and cleaved with $\mathrm{CNBr}$. As expected two sequences could be followed when the mixture was exposed to EDMAN degradation. Since one sequence was already known the unknown part of the second peptide could be determined and the sequence of T5-1 extended to 28 residues.

Digestion of T5-1 with CPD-Y gave the following sequence: Asp-Phe-Ser-Leu, which is known to be the C-terminus of CPD-Y as determined on native CPD-Y by us and others (8). The complete amino acid sequence of T5-1 is shown in Table I and a comparison with the amino acid composition obtained from amino acid analysis shown in Table II.

Pool T6. This peptide pool was applied to the sequencer and proved to be a mixture of peptides containing among others T5. An attempt to separate the peptides by means of high-voltage paper electrophoresis failed. Since the best strategy using the liquid phase sequencer is primarily to work with large peptides no further attempt was made to obtain the peptides contained in pool 6 .

\subsection{Digestions with other enzymes}

Overlaps between the peptides obtained by cleavage with cyanogen bromide described in the preceeding paper and the tryptic peptides described above only permitted the reconstruction of parts of the total sequence of CPD-Y. In order to obtain peptides necessary for additional overlaps cleavage was performed with A.mellea protease, chymotrypsin, post-proline cleaving enzyme and subtilisin Carlsberg. Some of the resulting peptides are discussed below, but only those of importance for the overlaps are included. Many more peptides were obtained in pure or partially purified form which confirmed sequences already determined as $\mathrm{CNBr}$-peptides or tryptic peptides.

Gel filtration of the peptide mixture obtained by cleavage with A.mellea protease gave rise to five peaks (called AM 1 to 5). The content of each of the peaks was sequenced 4 to 5 steps to check the purity. Two peaks, AM-3 and AM-4, were found to contain only two peptides each, one known and one unknown and consequently they were sequenced as far as possible.

AM-3 contained the sequence Lys-Asp-CysGlu- etc. already known as the $\mathrm{N}$-terminal sequence of tryptic peptide T4-7. The other sequence became: Lys-Gly-Gin-Asp-Phe-His-IleAla-Gly-Glu-Ser-Tyr-Ala-His-Gly-Tyr-Ile-Pro-

Val-Phe-. Part of this sequence was already known as the peptide containing the active site serine $(17,8)$. AM-4 consisted of the peptide Lys-Ala-Trp-Thr- etc. already known as part of cyanogen bromide peptide $\mathrm{CNBr}$ II. The other peptide became: Lys-Asp-Val-Tyr-Asn-Phe-LeuGlu-Leu-Phe-Phe-Asp- ? -Phe-Pro-Glu-Tyr--. (called AM-4).

Peptide pool AM-1 contained several peptides which were further purified by ion-exchange chromatography (see 2.2.4.).The peak emerging in front contained a pure peptide which gave the following sequence: Lys-Pro-Ile-Gly-Asn-ProTyr-Ser-Trp-Asn-Ser- ? -Ala-Thr-Val-Ile-PheLeu. The sequence will be referred to as AM-1.

When the peptides from a digestion mixture not retained by ConA (see 2.2.5.) was separated on Sephadex G50 four peaks were obtained. One peak, in the following referred to as AM-ConA, contained a major peak ( $80 \%$ of total) which upon sequencing gave the following result: Lys-Val-Arg-Cys-Trp-Thr-Ala-Ser-Ile-Thr-AspGlu-Val-Ala-Gly-Glu-Val-Lys- ? -Tyr.

Initial separation of the mixture of chymotryptic peptides of CNBr II on Sephadex G50 followed by further separation on Sepharose 4B led to the partial purification ( $50 \%$ ) of a peptide (called CT 1) the sequence of which was: Ala- 
Ser-Gin-Lys-Val-Arg-. It was not possible to extend the sequence any further since the peptide disappeared abruptly at this stage.

Peptides obtained by cleavage with postproline cleaving enzyme were partially separated on Biogel P30 and checked on the sequencer by running 3 to 4 steps of each of the resulting peaks. It immediately became evident that the enzyme had not hydrolyzed any of the expected bonds in the known part of the sequence of $\mathrm{CNBr}$ II. In contrast, peptides compatible with tryptic activity was easily detected. A nonapeptide was isolated in nearly pure state with the amino acid composition: Thr 1, Ser $1, \mathrm{Leu}_{1}, \mathrm{Tyr}_{2}$, Phe $_{1}$, His 1, Lys $_{1}$, Arg $_{1}$. The following sequence was obtained: Ser-Tyr-Lys-His-Phe-Thr-Tyrwhich must be followed by Leu-Arg. This peptide is apparently obtained by limited proteolysis probably due to an impurity in the commercial preparation of post proline cleaving enzyme.

Upon gel filtration on Biogel P30 of the peptides resulting from cleavage of CPD-Y with subtilisin Carlsberg two peaks emerged, in the following named SI and S2. Peak S1 was rechromatographed and lyophilized. When sequenced it was shown to consist of two peptides one of which was the known N-terminal sequence of CPD-Y. The other sequence actually consisted of two sequences one amino acid out of phase. The sequence of the longest peptide was as follows: Ser-Tyr-Ala-His-Gly-Tyr-Ile-Pro-ValPhe-Ala- ? -Glu-Ile-Leu-His-Lys-Asp-Arg-AsnPhe- ? -Leu-Thr. Thus, cleavage had taken place on both sides of the serine residue, which is the residue in the active site (see below).

When cyanogen bromide peptide $\mathrm{CNBr}-\mathrm{D}_{\mathrm{I}}$ (17) was digested with $S$. aureus V8 protease and the resulting peptides separated by HPLC (see 2.2.9.) a peptide with the amino acid composition Asp2, Glu $2, G_{2}$, Ala1, Val 1 , Ile, Tyr 1 , $\mathrm{Phe}_{1}$, His 1 , Lys 1 was isolated and sequenced seven steps: Tyr-Val-Asn-Lys-Gly-Gin-Asp. This peptide will be referred to as peptide SP 1 .

\section{DISCUSSION}

\subsection{Tryptic peptides}

According to amino acid analysis of CPD-Y $(8,10,13)$ the enzyme contains 9 or 10 arginine residues per molecule. Blocking the lysine sidechains by citraconylation followed by digestion with trypsin should therefore lead to the appearance of 10 or 11 peptides. As seen in Table I eight peptides have been partly or completely sequenced. One of these, T4-2 (imp) was sequenced as a minor component or impurity in the T4-2 peptide. The peptide T2 contains two arginine residues according to the amino acid analysis and it is anticipated that the peptide T4-2(imp) has arisen from $\mathrm{T} 2$ by incomplete tryptic cleavage. If this is correct a peptide with a smaller molecular weight than $\mathrm{T} 2$, but the same $\mathrm{N}$-terminal sequence must exist. This peptide was found in the T3 pool of peptides.

Two more tryptic peptides have been sequenced as part of cyanogen bromide peptide CNBr$\mathrm{W}_{\text {II }}$ (17). One is a tripeptide: Thr-Gly-Arg, and the other is a hexapeptide: Asn-Val-Tyr-Asp-IleArg, both too small to be included in the peptides sequenced in the present work. Nine arginine residues are thus accounted for, probably the correct number of this amino acid in the molecule of CPD-Y.

\subsection{Alignment of peptides}

The information contained in the amino acid sequences described in this and the preceeding paper permits the reconstruction of the major part (approximately 96\%) of the amino acid sequence of CPD-Y, which is shown in Figure 4. The numbering system used in the discussion below refers to that of Figure 1. The numbers beyond residue 114 are arbitrary and serve only as a help in identifying the discussed peptides as they appear in the reconstructed sequence.

Residue 1 to 44 of the N-terminal part of CPD-Y were determined by sequencing the

Figure 4. Partial amino acid sequence of carboxypeptidase $Y$.

$\rightarrow$ Denotes amino acids sequenced in the various peptides the nomenclature of which is given on the left side of the figure; for explanation, see section 4.2.

$\uparrow$ Denotes tentative assignment of carbohydrates. … Denotes unidentified sequence. Sếr denotes the serine residue in the active site. The numbering from residue 126 to 430 is arbitrary and serves only to guide the reader. 


\section{SvENDSEN et al.: Amino acid sequence of CPD-Y}

$10 \quad \hat{P} 20$

Lys-Ile-Lys-Asp-Pro-Lys-Ile-Leu-Gly-Ile-Asp-Pro-Asn-Val-Thr-Gln-Tyr-Thr-Gly-Tyr-Leu-Asp-Va]-Glu-Asp-

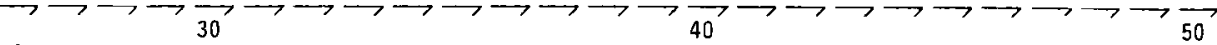

Glu-Asp-Lys-His-Phe-Phe-Phe-Trp-Thr-Phe-Glu-Ser-Arg-Asn-Asp-Pro-Ala-Lys-Asp-Pro-Val-Ile-Leu-Trp-Leu-

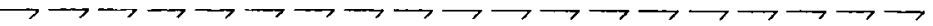

T1 CNBr-D,

T1 $\mathrm{CNBr}-\mathrm{D}_{1}$

$\mathrm{CNBr}-\mathrm{D}_{1}$

AM-1

$\mathrm{CNBr}-\mathrm{W}$

$\mathrm{CNBr}_{1}$

AM-4

$S P-1$

AN-3

AM-3

S-1

T3-6

$5-1$

T3-6

T3-6 CNBrI-II

CNBrI-I $\mathrm{CNBr}-\mathrm{W}_{\text {II }}$

60 $\longrightarrow \longrightarrow \longrightarrow \longrightarrow \longrightarrow$ $\overrightarrow{70} \rightarrow \longrightarrow \longrightarrow \longrightarrow \longrightarrow$

Asn-Gly-Giy-Pro-Gly-Cys-Ser-Ser-Leu-Thr-Gly-Leu-Phe-Phe-Glu-Leu-Gly-Pro-Ser-Ser-Ile-Gly-Pro-Asp-Leu$\longrightarrow \longrightarrow \longrightarrow \longrightarrow \longrightarrow \longrightarrow \longrightarrow \longrightarrow \longrightarrow \longrightarrow \rightarrow \longrightarrow \rightarrow$

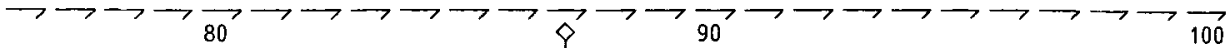

Lys-Pro-Ile-Gly-Asn-Pro-Tyr-Ser-Trp-Asn-Ser-Asn-Ala-Thr-VaT-Ile-Phe-Leu-Asp-Gln-Pro-Val-Asn-Val-Gly$\longrightarrow \longrightarrow \longrightarrow \longrightarrow \longrightarrow \longrightarrow$

$$
\overrightarrow{110} \longrightarrow \longrightarrow \longrightarrow \longrightarrow \longrightarrow \longrightarrow \longrightarrow \longrightarrow \longrightarrow \longrightarrow \longrightarrow \longrightarrow
$$

Phe-Ser-Tyr-Ser-Gly-Ser-Ser-Gly-Val-Ser-Asn-Thr-

$\longrightarrow \longrightarrow \longrightarrow \rightarrow \longrightarrow \rightarrow \longrightarrow \rightarrow \longrightarrow \rightarrow \longrightarrow \rightarrow \longrightarrow$

140

Lys-Asp-Val-Tyr-Asn-Phe-Leu-Glu-Leu-Phe-Phe-Asp- -Phe-Pro-Glu-Tyr-Val-Asn-Lys-Gly-Gln-Asp-Phe-His$\longrightarrow \longrightarrow \longrightarrow \longrightarrow \longrightarrow \longrightarrow \longrightarrow \longrightarrow \longrightarrow \longrightarrow \longrightarrow \longrightarrow \longrightarrow$

Ile-Ala-Gly-Glu-Sér-Tyr-Ala-His-Gly-Tyr-Ile-Pro-Val-Phe-Ala- $\quad$-Glu-Ile-Leu-Ser-His-Lys-Asp-Arg-Asn$\longrightarrow \longrightarrow \longrightarrow \longrightarrow \longrightarrow \longrightarrow \longrightarrow \longrightarrow \longrightarrow \longrightarrow \longrightarrow \longrightarrow$

$$
8 \quad 180 \quad 190 \quad \overrightarrow{200}
$$

Phe-Asn-Leu-Thr-Ser-Val-Leu-Ile-Gly-Asn-Gly-Leu-Thr-Asp-Pro-Leu-Thr-Gln-Tyr-Asn-Tyr-Tyr-Glu-Pro-Met$\longrightarrow \longrightarrow \longrightarrow$

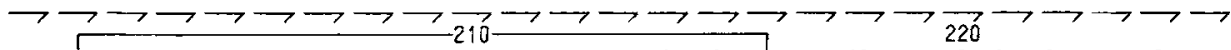

Ala-Cys-Gly-GTu-Gly-Gly-GIu-Pro-Ser-VaI-Leu-Pro-Ser-Glu-Glu-Cys-Ser-Ala-Met-Glu-Asp-Ser-Leu-GIu-Arg-

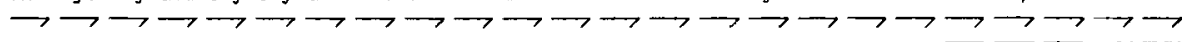

$230 \quad 240 \quad \longrightarrow \rightarrow \longrightarrow \longrightarrow$

Cys-Leu-Gl y-Leu-I le-Glu-Ser-Cys-Tyr-Asp-Ser-Gln-Ser-Val-Trp-Ser-Cys-Val-Pro-Ala-Thr-I le-Tyr-Cys-Asn-

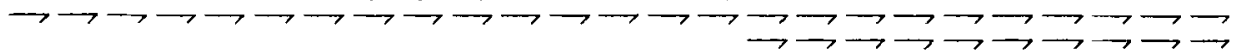

260

270

Asn-Ala-Gln-Leu-Ala-Pro-Tyr-GIn-Arg-Thr-Gly-Arg-Asn-Val-Tyr-Asp-Ile-Arg-Lys-Asp-Cys-Glu-Gly-Gly-AsnCNBrI-II $\longrightarrow \longrightarrow \longrightarrow \longrightarrow \longrightarrow \longrightarrow \longrightarrow$



T4-7

Leu-Cys-Tyr-Pro-Thr-Leu-Gln-Asp-Ile-Asp-Asp-Glu-Leu-Asn-Gln-Asp-Tyr-Val-Lys-Glu-Ala-Val-Gly-Ala-GIu-

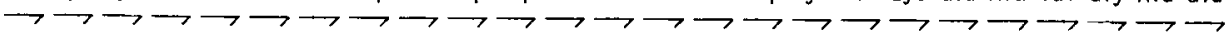
310

320

Val-Asp-His-Tyr-Glu-Ser-Cys-Asn-Phe-Asp-Ile-Asn-Arg-Asn-Phe-Leu-Phe-Ala-Gly-Asp-Trp-Met-Lys-Pro-Tyr-

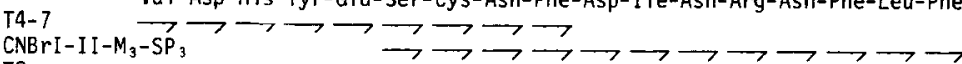

T2

330

$\longrightarrow \longrightarrow \longrightarrow$

340

His-Thr-Ala-Val-Thr-Asp-Leu-Leu-Asn-Gln-Asp-Leu-Pro-Ile-Leu-Val-Tyr-Ala-G1y-Asp-Lys-Asp-Phe-Ile-Asn-

12

CNBr II

CNBr II

CT-1

AM-CONA

CNBr II

CT-1

AM-CONA

CNBr-HII

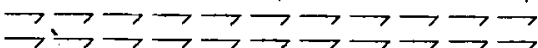

$\overrightarrow{360} \longrightarrow \longrightarrow \longrightarrow \longrightarrow \rightarrow \longrightarrow \rightarrow \longrightarrow \longrightarrow$

Asn-Thr-Leu-Gly-Asn-Lys-Ala-Trp-Thr-Asp-Val-Leu-Pro-Trp-Lys-Tyr-Asp-Glu-Glu-Phe-Ala-Ser-Gln-Lys-Val-

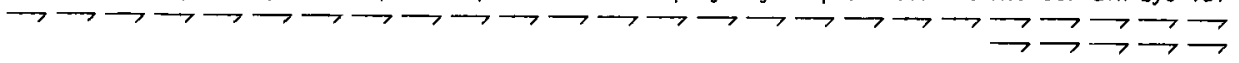

380

390

400

Arg-Cys-Trp-Thr-Ala-Ser-Ile-Thr-Asp-Glu-Val-Ala-Gly-Glu-Val-Lys-Ser-Tyr-Lys-His-Phe-Thr-Tyr-Leu-Arg-

$\longrightarrow$

$$
\longrightarrow
$$

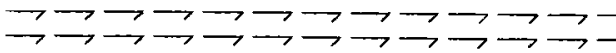

410

Val-Phe-Asn-Gly-Gly-His-Met-Val-Pro-Phe-Asp-Val-Pro-Glu-Asn-Ala-Leu-Ser-Met-Val-Asn-Glu-Trp-Ile-His-

Gly-Asp-Phe-Ser-Leu

$$
\longrightarrow \vec{\longrightarrow} \longrightarrow
$$


native enzyme (17) and provided a six residue overlap to tryptic peptide $\mathrm{T} 1$ which starts at residue Asn(39). This peptide was sequenced through Glu(65). Most of the sequence was contained in that of $\mathrm{CNBr}$-peptide $\mathrm{CNBr}-\mathrm{D}_{\mathrm{I}}$ (17), the sequencing of which brought the sequence to Trp(84). Peptide AM-1, obtained by cleavage with A.mellea protease started at Lys(76), extended the sequence to Leu(93) and provided a 9 residue overlap to the sequence of cyanogen bromide peptide $\mathrm{CNBr}-\mathrm{W}_{\mathrm{I}}$ which starts at Asn(85) and was followed through Ala(114).

At this stage the continuous sequence is interrupted and a gap of 11 residues is inserted, a number which is only approximately correct since it depends on the accuracy of the amino acid analysis of CPD.Y.

The continuous sequence of CPD-Y is resumed again at residue Lys (126) by the peptide AM-4 which was sequenced 17 residues whereby an overlap of one residue was established to peptide SP-1. This peptide was sequenced seven steps. The last four residues sequenced were recognized as the first four amino acids of peptide AM-3, which starts Lys(145)-Gly(146)$\mathrm{G} \ln (147)$.

In view of the few residues left to be sequenced ( 10 to 20 residues) we find it justified to join peptides AM-4 and SP-1 based on an overlap of only one residue and a correct located Glu with respect to cleavage by S.aureus protease.

Peptide AM-3 was sequenced 20 steps through Phe (164) and overlapped ten residues with peptide SI obtained by cleavage with subtilisin Carlsberg. Peptide S1 was sequenced through $\mathrm{Thr}(179)$ and overlapped in five positions with the tryptic peptide T3-6.

Peptide T3-6 was sequenced 50 steps through Glu(224) where an overlap of five residues was established with cyanogen bromide peptide CNBr I-II. This peptide extended the sequence to residue $G \ln (258)$. Another cyanogen bromide peptide, $\mathrm{CNBr}-\mathrm{W}_{\mathrm{II}}$, which started at $\operatorname{Ser}(241)$ (thus repeating a substantial part of $\mathrm{CNBr}$ I-II) was sequenced through Leu(276) whereby an overlap of 8 residues with tryptic peptide T4-7 was evident.

A peptide obtained from cleavage with $\mathbf{S}$. aureus protease, CNBr I-II-M3-SP3 (17), started at $\operatorname{Ser}(282)$ and was sequenced through
Phe(293) whereby an overlap of four residues was established to tryptic peptide $\mathrm{T} 2$.

At residue Lys(299) the sequence of $T 2$ joins that of cyanogen bromide CNBr II which was sequenced 56 residues of which the first 13 overlapped with T2. Although some unassigned residues appeared within the last 10 residues of $\mathrm{CNBr}$-II those which was assigned functioned as valid markers for providing the necessary overlap. Thus, the chymotryptic peptide CT-1 starting Ala(371)-Ser(372)-Gln(373)- and the peptide AM-ConA which started Lys(374)Val(375)-Arg(376) double checked this part of the sequence and the latter peptide provided the overlap to cyanogen bromide peptide $\mathrm{CNBr}-\mathrm{W}_{\text {III }}$ (17). This peptide was sequenced through $\operatorname{Thr}(397)$ and identified the six first residues of the "sunorthodox" peptide beginning $\operatorname{Ser}(392)$ Tyr(393)-Lys(394)- obtained by cleavage with post-proline cleaving enzyme.

Sequencing of the latter peptide extended the sequence to $G l y(405)$ and gave a five residue overlap to tryptic peptide T5-1, which was sequenced almost to the end extending the sequence of CPD-Y to residue Phe(428). The four C-terminal residues of CPD-Y are Asp-PheSer-Leu as determined by treatment with native CPD-Y and it is seen from Figure 4 that a two residue overlap to T5-1 is established.

\subsection{Assignment of carbohydrate moieties}

CPD-Y as prepared from baker's yeast in our laboratory (10) contains about $23 \%$ carbohydrates. Evidence has been presented for the attachment of the carbohydrate moieties at only four asparagine side-chains $(6,21)$. When carbohydrates are linked through asparagine side-chains there is a great chance that the amino acid sequence will be: Asn-X-Thr/Ser (9). We have tentatively identified the four positions in CPD$\mathrm{Y}$ which carry carbohydrates. The $\mathrm{N}$-terminal peptide, T4-5, contained carbohydrate and the only position not assigned to an amino acid was No. 13 which therefore most likely contains an Asn carrying carbohydrate. It is noted that a Thr occupies position 15 .

Tryptic peptide T3-6 also contains carbohydrate. This peptide has been completely sequenced and the only position vacant for a carbohydrate moiety is residue 177 (in Figure 4). 
Furthermore, a Thr occupies position 179, therefore a carbohydrate moiety is placed in position 177.

Tryptic peptide $\mathrm{T} 2$ contains carbohydrate and so does the $\mathrm{CNBr}$-peptide (CNBr III) (17) which overlaps with $\mathrm{T} 2$. Both peptides have been completely sequenced and the only empty position is No. 350 (in Figure 4) to which a carbohydrate moiety consequently is assigned. A Thr is noted in position 352 .

Finally, the fourth carbohydrate moiety has been placed in position 87 (in Figure 4). The argument for this decision is that cyanogen bromide fragment $\mathrm{CNBr}-\mathrm{W}_{1}$ contained carbohydrate, position 3 in that peptide was empty and a Thr occupied position 5 . Since CNBr-W I extends into the region not yet sequenced the possibility still exists that the carbohydrate is located here. However, in that case the empty position 87 will be difficult to explain.

\subsection{Assignment of disulphide bridges}

No direct attempts have been made to determine the disulphide bridges in carboxypeptidase $\mathrm{Y}$. One bridge can be assigned, however, since it was located in a small cyanogenbromide peptide derived from cleavage of CPD-Y which was not reduced and pyridylethylated (17). In Figure 4 the peptide comprises residues 201 to 219. It is seen to contain two cysteine residues. If one of these was the free cysteine residue $(1,7)$ the other had to be linked to a different peptide. Since this was not the case it was concluded that a bridge exists between Cys(202) and Cys(217). The number of half-cystines determined by amino acid analysis varies $(8,10,13)$, but eleven cysteine residues have been located by the sequence studies. In light of the few residues remaining to be determined 11 Cys is probably the correct number. Thus four disulphidebridges remain to be determined.

\subsection{Sequence comparison with other proteases}

Although the amino acid sequence of carboxypeptidase $\mathrm{Y}$ is not yet complete it is relevant to make comparisons with other proteases on the basis of the partial sequence shown in Figure 4.

Only two carboxypeptidases are well characterized with respect to amino acid sequence, viz. the pancreatic enzymes carboxypeptidase $A$ and B. No homology was observed with these enzymes. However, they are metallo-enzymes while CPD-Y is a "serine" protease with a quite different catalytic mechanism. A carboxypeptidase which also is a wserine protease « has been isolated from French beans (19). However, the only sequence yet published is the Glu-Ser-Tyr active site peptide, which is identical to that found in CPD.Y.

When the sequence of CPD.Y was compared to those of the pancreatic serine proteases chymotrypsin, trypsin and elastase no homology

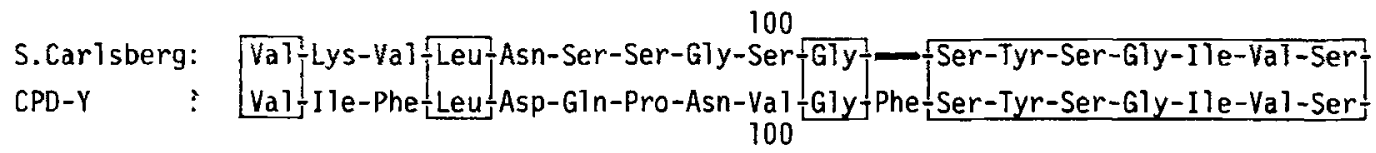

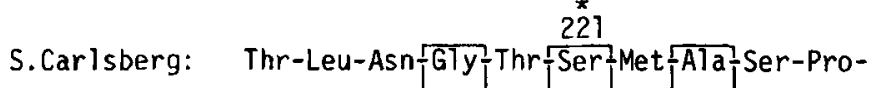

$$
\begin{aligned}
& \text { CPD-Y : His-Ile-Ala-Gly Glu-Ser Tyr-Ala } \\
& \text { S.Carlsberg: Asn Thr Ile-Giy-Tyr Tro Ala Lys-Tyr-Asp-Ser-Val Ile-Ala Val-Gly-ATa Val } \\
& \text { CPD-Y : Trp-Thr-Asp-Val-Leu LProfTrp LLSS-Tyr-Asp-Glu-GluLIle-Ala-Ser-GIn-Lys-Val }
\end{aligned}
$$

Figure 5. Sequence homologies between subtilisin Carisberg and carboxypeptidase $Y$.

Denotes gap introduced to maximize homology. Sêr denotes the serine residue in the active site. Identical amino acids in the two sequence are boxed. 
was observed. However, comparison with the bacterial serine protease subtilisin Carlsberg revealed homologous sequences. Thus, the sequence Val92-Ser 109 in CPD-Y compared well with the sequence $\mathrm{Val}_{92}$-Ser ${ }_{108}$ in subtilisin Carlsberg provided a gap is introduced in the latter sequence (see Figure 5). Also, the sequence Asn ${ }_{163}-V_{a l}{ }_{180}$ in subtilisin Carlsberg showed homology with the sequence $\operatorname{Trp}_{333}-\mathrm{Val}_{350}$ in CPD-Y (see Figure 5). It is doubtful, however, if these homologies have any relevance since no homologies have been found in other parts of the molecules.

In conclusion, it appears that carboxypeptidase $Y$ represents a unique class of enzymes not related to any of the proteases known to day.

\section{ACKNOWLEDGEMENTS}

The authors wish to express their appreciation to Professor Martin Ottesen for his continued encouragement and helpful discussion during the course of this work. The excellent technical assistance of Lone SøRensen and Bodil CoRneLUUSSEN is gratefully acknowledged. Brian MARTIN thanks the board of the Carlsberg Laboratory for financial support.

\section{REFERENCES}

1. Bal, Y. \& R. HaYashi: A possible role for a single cysteine residue in carboxypeptidase $\mathrm{Y}$. FEBS Lett. 56, 43-45 (1975)

2. Dixon, H. B. F. \& R. N. Perham: Reversible blocking of amino groups with citraconic anhydride. Biochem. J. 109, 312-314 (1968)

3. Drapeau, G. R., Y. Bolly \& J. Houmard: Purification and properties of an extracellular protease of Staphylococcus aureus. J. Biol. Chem. 247, 6720-6726 (1972)

4. Dubois, M., K. A. Gilles, J. K. Hamilton, P. E. Rebers \& F. SMITH: Colorimetric method for determination of sugars and related substances. Anal. Chem. 28, 350-356 (1956)

5. Friedman, M., L. H. Krull \& J. F. Cavins: The chromatographic determination of cystine and cysteine residues in protein as $\mathrm{S}-\beta$-(4-pyridylethyl) cysteine. J. Biol. Chem. 245, 3868-3871 (1970)

6. Hasilik, A. \& W. TANNER: Carbohydrate moiety of carboxypeptidase $\mathrm{Y}$ and perturbation of its biosynthesis. Eur. J. Biochem. 91, 567-575 (1978)
7. Hayashi, R.: Carboxypeptidase Y. In: Methods Enzymol, vol XLV, part B, L. Lorand, ed., pp 568 (1976)

8. Hayashi, R., S. Moore \& W. H. Stein: Carboxypeptidase from yeast. Large scale preparation and the application to $\mathrm{COOH}$-terminal analysis of peptides and proteins. J. Biol. Chem. 248, 2296-2302 (1973)

9. Hunt, L. T. \& M. O. Dayhoff: The occurrence in proteins of the tripeptides Asn-X-Ser and Asn-X-Thr and of bound carbohydrate. Biochem. Biophys. Res. Commun. 39, 757-765 (1970)

10. Johansen, J. T., K. Breddam \& M. Ottesen: Isolation of carboxypeptidase $\mathrm{Y}$ by affinity chromatography. Carlsberg Res. Commun. 41, 1-14 (1976)

11. Johansen, J. T., C. Overballe-Petersen, B. Martin, V. Hasemann \& I. Svendsen: The complete amino acid sequence of copper, zinc superoxide dismutase from Saccharomyces cerevisiae. Carlsberg Res. Commun. 44, 201-217 (1979)

12. Klapper, D. G., C. E. Wilde III \& J. D. Capra: Automated amino acid sequence of small peptides utilizing Polybrene. Anal. Biochem. 85 , 126-131 (1978)

13. Kuhn, R. W., K. A. Walsh \& H. Neurath: Isolation and partial characterization of an acid carboxypeptidase from yeast. Biochemistry 13 , 3871-3877 (1974)

14. KULBE, K. D.: Micropolyamide thin-layer chromatography of phenylthiohydantoin amino acids (PTH) at subnanomolar level. A rapid microtechnique for simultaneous multisample identification after automated Edman degradations. Anal. Biochem. 59, 564-573 (1974)

15. Lewis, W. G., J. M. Basford \& P. L. Walton: Specificity and inhibition studies of Armillaria mellea protease. Biochim. Biophys. Acta 522, 551-560 (1978)

16. Martin B., I. Svendsen \& M. Ottesen: Use of carboxypeptidase $\mathrm{Y}$ for carboxylterminal sequence determination in proteins. Carlsberg Res. Commun. 42, 99-102 (1977)

17. Martin, B., I. Svendsen, T. Viswanatha \& J. T. JohanSEN: Amino acid sequence of carboxypeptidase Y. I. Peptides from cleavage with cyanogenbromide. Carlsberg Res. Commun. 47 , 000-000 (1982)

18. Mendez, E. \& C. Y. LaI: Regeneration of amino acids from thiazolinones formed in the Edman degradation. Anal. Biochem. 68, 47-53 (1975)

19. Shaw, D. C. \& J. R. E. Wells: Radiochemical determination of a unique sequence around the reactive serine of a di-isopropyl phosphorofluor- 
idate-sensitive plant carboxypeptidase and a yeast peptidase. Biochem. J. 128, 229-235 (1972)

20. Suendsen, I., B. Martin \& I. Jonassen: Characteristics of hiproly barley. III. Amino acid sequences of two lysine-rich proteins. Carlsberg Res. Commun. 45, 79-85 (1980)
21. Trimble, R. B. \& F. Maley: The use of endo- $\beta$ $\mathrm{N}$-acetylglucosaminidase $\mathrm{H}$ in characterizing the structure and function of glycoproteins. Biochem. Biophys. Res. Commun. 78, 935-944 (1977) 